\title{
Vasos para el otro mundo: cinco ejemplos de vasos ceremoniales encontrados en una mano de los fardos de personajes de la élite sicán
}

\author{
Paloma CArcedo de Mufarech \\ Universidad de Lima, Perú \\ palomacarcedo@hotmail.com
}

Recibido: 15 de octubre de 2013

Aceptado: 25 de noviembre de 2013

\begin{abstract}
RESUMEN
En las últimas dos décadas las excavaciones realizadas por el Proyecto Arqueológico Sicán en el Santuario Histórico Bosque de Pómac en Batán Grande, valle medio del río La Leche, costa norte del Perú, han producido el hallazgo de tumbas, más o menos complejas, de personajes de la élite de la cultura Sicán o Lambayeque, del periodo Sicán Medio (900-1100 d.C.), en donde el fardo del personaje principal, con brazos y manos postizas, lleva en una de ellas un vaso característico en señal de brindis con los dioses o ancestros en su tránsito a la otra vida. En este trabajo analizamos cinco vasos encontrados en fardos de diferentes personajes de la élite, cuatro excavados en la Huaca Loro y uno en la Huaca Las Ventanas, ambas ubicadas en el Recinto Ceremonial Sicán. Estos vasos muestran características morfológicas e iconográficas propias que difieren del resto de vasos del mismo periodo estudiados por la autora.
\end{abstract}

Palabras clave: Vasos de metal, cultura Sicán o Lambayeque, iconografía sicán, ritos funerarios.

\section{Vessels for the Other World: Five Examples of Ceremonial Vessels Held on One Hand of Sican Elite Funerary Bundles}

\begin{abstract}
Excavations over the last two decades by members of the Sican Archaelogical Project (PAS) at the Pómac Forest Historical Sanctuary in Batán Grande, in the middle La Leche Valley on the Peruvian North Coast, have produced the discovery of Middle Sican period (AD 900-1000) elite tombs, with a certain degree of complexity, where main funerary bundles have fake arms and hands, and hold a characteristic vase on one hand as a toast to gods or ancestors in the journey to another life. We analyze five such vases, four of them from Huaca Loro and one from Huaca Las Ventanas, both located at the Sican Ceremonial Site. This vases show morphological and iconographic characteristics that are unique and differ from the rest of Middle Sican vases previously studied by the author.
\end{abstract}

Key words: Metal vases, Sican or Lambayeque Culture, Sican iconography, funerary rituals.

Sumario: 1. Introducción. 2. Iconografía y forma de los cinco vasos. 3. Similitudes y diferencias entre los cinco vasos. 4. Conclusiones. 5. Referencias bibliográficas.

«Para este brindarse que unos a otros se hacían, es de saber que todos estos indios generalmente, cada uno en su tanto, tuvieron -y hoy tienen- los vasos para beber todos hermanados, de dos en dos: o sean grandes o chicos, han de ser de un tamaño, de una misma hechura, de un mismo metal, de oro o plata o de madera. Y esto hacían por que hubiese igualdad en lo que se bebiese. El que convidaba a beber llevaba sus dos vasos en las manos, y si el convidado era de menor calidad, le daba el vaso de la mano izquierda, y si de mayor o igual, el de la derecha, con más o menos comedimiento, conforme al grado o calidad del uno y el otro, y luego bebían ambos a la par» (Garcilaso de la Vega 2004 [1609]: p. 376 [Libro VI, Capítulo XXIII]). 


\section{Introducción}

Es difícil que la culminación de un acontecimiento importante en nuestros días no vaya acompañada del acto de compartir una bebida con los celebrantes como señal de amistad, acuerdo alcanzado o simplemente júbilo y respeto por la celebración. En las culturas antiguas, y en concreto las precolombinas de los Andes Centrales, la costumbre de brindar y festejar era fundamental para compartir, transmitir y mantener las creencias y actos de reciprocidad de una comunidad o cultura. Música, danza y bebida eran componentes esenciales para la realización de rituales que mantenían viva su concepción sobre la vida, cosmovisión o vinculación con los dioses y ancestros (véase Cummins 2004; Flores et al. 1998). Por lo tanto, las libaciones y los líquidos y, por consiguiente, los vasos como recipientes de estos -ya sea como contenedores de chicha o sangre en los rituales cruentos o cualquier sustancia psicoactiva o bebida fermentada- jugaron un papel esencial en la celebración tanto en los rituales relacionados con la vida terrenal como en los dedicados a los dioses, difuntos o a la otra vida.

No podemos olvidar que antiguamente los rituales relacionados con la muerte y los ancestros eran tan importantes como los realizados para los vivos, y que los mundos de vivos y muertos se fundían en uno solo, cohabitaban e interactuaban sin que hubiera una línea divisoria entre ambos. Para Kaulicke, «la transformación iniciada con la muerte física, la que es la misma del inicio del proceso de la ancestralidad ... implica una fuerza generatriz de bienestar concentrada en el ancestro, pero, al parecer, transferible a otros» (Kaulicke 2001: 325). La costumbre de compartir comida, bebida y música, con y entre vivos y difuntos, era pues parte de la manera de entender el mundo y cohabitar en él.

Cronistas como Guamán Poma de Ayala, Cieza de León, Arriaga y Garcilaso de La Vega, describen en muchas ocasiones la importancia y el uso de los vasos -tanto de oro y plata como de madera- en las libaciones colectivas en el contexto de diversas fiestas o conmemoraciones que tuvieron la ocasión de presenciar durante las primeras décadas de la conquista. Son varios los dibujos de Guamán Poma en que encontramos a los vasos como protagonistas, formando parte de escenas diversas, ya sea el Inca brindando con el dios Sol y rindiéndole culto (Guamán Poma 1993 [1615], Tomo 1: 78), capitanes de élite brindando antes de una batalla (ibid:: 115), en escenas de meses del calendario inca vinculado a la fiesta de junio del Inti Raimi (ibid.: 182) o del mes de agosto en «la fiesta de la labranza» (ibid.: 185). Pero en nuestro caso, el interés se centra en los rituales de entierros y celebraciones con los difuntos. Protagonista fundamental en estos era la chicha, bebida por excelencia en todos los rituales (Arriaga 1999 [1621]: 50). Estaba elaborada mediante la maceración principalmente de maíz pero también de otros vegetales como son la yuca o el maní. Sabemos por la iconografía que otras culturas como la Moche (0-750 d.C.) realizaban sacrificios cruentos y que la sangre era ofrecida a las deidades en una copa ceremonial, pero no tenemos datos de que las copas encontradas como ofrenda en los entierros moche hubieran sido usadas como contenedores de sangre. Cieza de León es quizás el cronista que mejor describe los diferentes tipos de rituales, ceremonias funerarias y formas de sepultar a los grandes señores en varias partes del Perú. Concretamente, nos fijaremos 
en la descripción de los entierros en la isla de la Puná, cerca del puerto de Tumbes, a 400 km de Batán Grande:

«Quando los señores se mueren, son muy llorados por toda la gente della, asi hombres como mujeres: y entiérranlos con gran veneración a su uso, poniendo en la sepoltura cosas de las mas ricas que él tiene, y sus armas, y algunas de sus mujeres de las mas hermosas las quales como acostumbran en la mayor parte de estas Indias se meten vivas en las sepolturas para tener compañía a sus maridos» (Cieza de León 1995 [1553]: 174).

En dos ilustraciones, Guamán Poma muestra el uso de vasos con forma de kero en rituales funerarios ofreciéndole al fardo funerario la bebida. En uno, los oferentes son el Inca y la Coya, que están de pie, pero es el Inca quien ofrece la bebida vertiéndola mientras que la Coya observa y sujeta otro vaso en su mano (Guamán Poma de Ayala 1993 [1615]: 215). Esta forma de ofrecer beber al difunto la vemos en otro grabado donde se muestra la costumbre de enterramiento entre los indios del Collasuyo (ibid.: 220). En ambos casos es el hombre -el Inca y seguramente un alto dignatario de los Collasuyos- quien sujeta un vaso con una mano y en la otra lleva otro vaso con el que vierte el líquido (chicha) a un recipiente de gran tamaño. También en ambos hay una mujer que observa y participa del ritual bebiendo. Por lo tanto, quizás podamos entender que el Inca usa dos vasos: en uno bebe y el otro es para que beba el difunto, lo que se escenifica vertiendo el líquido al suelo; la mujer, la Coya, usa otro propio. Pero quizás más interesante para entender los vasos en los rituales funerarios es el ya mencionado dibujo del mes de junio, en donde el Inca «brinda con el sol» con un vaso mientras el otro es llevado por un genio alado a su padre el sol en presencia de la Coya, que vierte chicha en otros dos vasos (ibid.: 182). Es decir, ya no se brinda por honrar al difunto o ancestro, sino que el Inca brinda con la propia divinidad.

La costumbre de brindar con los dioses y con los difuntos o ancestros debió de estar muy difundida en todas las culturas precolombinas. Pero es solamente en la cultura Sicán que encontramos fardos que portan en una mano un vaso como signo de brindis con la divinidad. ¿Es el ancestro el mensajero que brinda con los dioses? ¿O brinda como fin de un acto de regeneración, convertido ya en ancestro? Alonso, en su estudio sobre las momias de los Incas (1989) y sobre los guauquis (1990a) o ídolos asociados a los Incas, determina que éstos eran a veces usados como sustitutos de las momias y expone que habría actividades diarias en torno a ellos que requerían de una dedicación completa: lavado, cambio de ropa, alimentación, protección de los insectos, adoración, preparación de las andas y celebración (Alonso 1989: 114). Compara estas actividades con un dibujo de un kero de la colección Juan Larrea del Museo de América de Madrid, en donde se representa una celebración con el Inca vivo, la Coya y la momia de uno de los anteriores Inca, escena muy parecida a la dibujada por Guamán Poma y comentada anteriormente. Si bien es cierto que las fiestas y rituales para difuntos son descritos por algunos cronistas, son pocos los que comentan las creencias indígenas en el más allá o en qué ocurría después de la muerte. Ya que los vasos aquí estudiados han sido encontradas en fardos funerarios, es interesante destacar las descripciones que sobre este tema realizan el propio Guamán Poma de Ayala y el padre Arriaga. El primero, describiendo las costumbres de los entierros de los indios 
del Collaysuyo, comenta cómo los muertos se reúnen en el más allá, llamado Caray pampa y Puquina, sea cual fuera su pertenencia:

«dicen que los reciben los difuntos y que van derecho a Caray pampa los Chinchaysuyos y Andesuyos; y los Collasuyos, Condesuyos se van los difuntos derecho a Puquina pampa y a Coropona, que allí se ajuntan. Y dicen que allí tienen mucha fiesta y conversación entre los difuntos y difuntas» (Guamán Poma 1993 [1615], Tomo I: 221).

El cronista Pablo Joseph de Arriaga comenta que el difunto, además de sentir, tiene la necesidad de comer y beber y de ahí que se entierre con comida y bebida junto al ajuar del muerto. También creían que sus almas inmortales iban a las huacas donde moraban pero que antes de llegar al «Upamarca» (tierra de los mudos) han de pasar unos «perros negros» (Arriaga 1999 [1621]: 76). Por lo tanto, el tema de la muerte en el antiguo Perú estuvo muy vinculado a creencias de transformación y tránsito a la otra vida. La muerte física del individuo era el inicio del proceso de transformación en el ancestro y el comienzo de otra vida.

Al morir, el individuo se regeneraba y pasaba a ser ancestro; como tal convivía y se identificaba con los dioses, convirtiéndose de esta manera en un potencial benefactor de la sociedad. Aquellos que por razones sociales o cualidades personales con su proceder aportaron un gran bien a un grupo determinado, cuando morían se convertían en el ancestro que desde el más allá les guiaría, protegería y ayudaría a permanecer fuertes como linaje. Este concepto obliga a mantener un constante y perenne cuidado de las momias y fardos de sus ancestros. Por ello, los descendientes deberán cuidar su cuerpo (momia), darle de beber, comer, cambiarles las ropas y realizar cultos en su honor, pues mientras esté vivo en la memoria de sus descendientes y de los otros grupos de poder estos tendrán o mantendrán su influencia entre los demás linajes. Como bien dice Kaulicke (2001: 287) «los muertos cohesionan al grupo, las genealogías que se remontan a un fundador mítico, constituyen una especie de historia que incluye a los muertos más antiguos, los gentiles y los lugares de enterramientos prehispanicos». Quizás sean los cronistas quienes más citas tienen sobre el culto a los ancestros y el cuidado que tuvieron en proteger los cuerpos momificados de los gobernantes, pues estos les protegían de futuros desastres escatológicos (Hernández 2012: 133). De ahí la importancia de situar los bultos y de los rituales que se hicieran en su nombre en lugares que pudieran ser vistos por una mayoría. Según Hernández (2012: 135), eran estos rituales que se celebraban durante las exequias del difunto los que le hacían pasar a la condición de ancestro; Betanzos va más lejos afirmando que era canonizado y tenido por santo.

Esta conversión en ancestro, que sólo los «privilegiados» alcanzaban, es interesante porque nos lleva a preguntarnos qué características habría que tener para lograrlo. ¿Ser respetado por la sociedad? ¿Buen guerrero o destacado artesano? Como vemos, la muerte y los rituales relacionados con el difunto eran parte de la vida de los antiguos. En este contexto, ¿cómo habría que interpretar los vasos que, como los cinco aquí analizados, se encuentran en una mano del difunto? Veamos primero sus características morfológicas e iconográficas para, luego, intentar establecer a través de ellas ciertos patrones de representación. 


\section{Iconografía y forma de los cinco vasos}

Vasos de oro y plata pertenecientes al periodo Sicán Medio ${ }^{1}$ se encuentran repartidos por colecciones públicas y privadas tanto en Europa como en América y todos provienen de tumbas saqueadas durante los años cincuenta y mediados de los sesenta en la antigua Hacienda de Batán Grande, que era propiedad de la familia Aurich (Carcedo y Shimada 1985). En 1991-92, el Proyecto Arqueológico Sicán (PAS) ${ }^{2}$ dirigido por el Dr. Izumi Shimada excavó por primera vez en la Huaca Loro una tumba intacta perteneciente a un personaje de la élite sicán que se conoce como la Tumba Este. En esta tumba se encontraron 1,2 toneladas de objetos, de los cuales el $80 \%$ eran metales. El personaje principal llevaba puesta la típica máscara sicán, siendo la primera vez que se documentaba su uso, así como unos desproporcionadamente largos guantes falsos de madera cubiertos de láminas doradas de metal que terminaban en unas manos, también falsas, en una de las cuales llevaba un vaso (véase, para más información, Shimada et al. 2004). Del año 1992 en adelante, el PAS ha encontrado in situ cuatro vasos rituales más portados por personajes de la élite sicán en una de sus manos. Este hecho, inusual en otras culturas precolombinas de los Andes Centrales, nos ha generado una serie de preguntas no sólo ligadas a su función como nexo entre las costumbres rituales del mundo de los vivos y de los ancestros, sino también en cuanto a la elección formal de estos vasos y el significado de las iconografías representadas en cada uno de ellos.

En investigaciones anteriores, se han distinguido diez grupos de vasos pertenecientes al Sicán Medio con características específicas (Carcedo 2012a). Los cinco vasos que se analizan aquí formarían un grupo diferente. En primer lugar, ninguno de ellos tiene pareja u otro similar ni en la tumba ni entre los mencionados grupos, mientras que los incluidos en éstos cuentan con uno o más -en algún caso hasta diez o doce- similares. En segundo lugar, y aunque el perfil campaniforme o forma de kero que muestran los cinco es común en los vasos de la cultura Sicán, cuatro de ellos guardan similitud en tamaño, forma e iconografía, distinguiéndose en esto del encontrado en la tumba de una mujer anciana en la Huaca Las Ventanas (véase más

\footnotetext{
1 El término sicán o sgnam en lengua nativa muchick, según recopilan algunos autores, significa «casa»o «templo» (can) de la luna (si), y se eligió para designar el área que ocupa la que actualmente se entiende como capital de la cultura Sicán, en el Santuario Histórico Nacional del Bosque de Pómac, situado en el valle medio del río La Leche, a $32 \mathrm{~km}$ al noreste de la ciudad de Chiclayo, en la costa norte de Perú. Dicha área, de unos $60 \mathrm{~km}^{2}$ y cubierta por un bosque seco de árboles de algarrobo, comprende una serie de montículos y cerca de 30 huacas (palabra quechua que significa objeto o lugar sagrado) de diversos tamaños y épocas. Las huacas más importantes pertenecientes al Sicán Medio son unos siete montículos similares en tamaño: Huaca Las Ventanas, La Merced -destruida en parte en 1983 por efecto de un episodio del fenómeno de El Niño-, Huaca Loro o Huaca Oro, El Corte, Rodillona o Lercanlech, Sontillo o Santillo y Moscón; estas dos últimas son las menores en tamaño. El Dr. Izumi Shimada ha establecido tres periodos para la cultura Sicán que abarcan en conjunto unos 600 años: Sicán Temprano (800-850 d.C.-900 d.C.), Sicán Medio (900-1100 d.C.) y Sicán Tardío (1100-1375 d.C.).

2 Dicho proyecto científico es dirigido, desde 1978 hasta la actualidad, por el Dr. Izumi Shimada. Durante estos 30 años de trabajos arqueológicos ininterrumpidos se han unido investigadores de diversas disciplinas y nacionalidades. Es, pues, un proyecto multidisciplinario y plurinacional. Las investigaciones se centran en dilucidar todos los aspectos de la cultura Sicán o Lambayeque, centrando las investigaciones en el área del Santuario Histórico Bosque de Pómac, en Batán Grande, capital política y religiosa de la cultura Sicán. La autora se unió al Proyecto en 1981.
} 

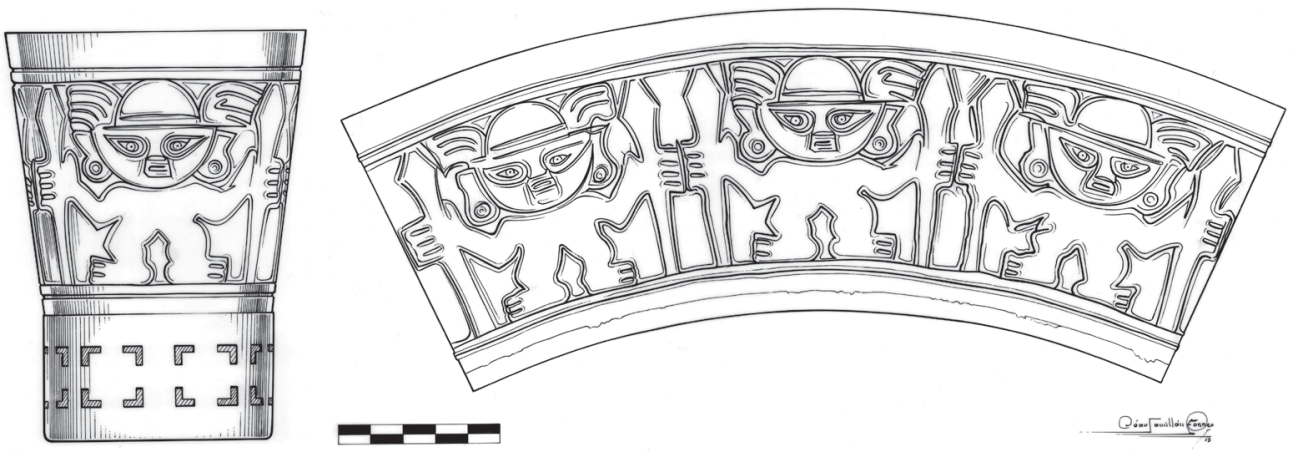

Figura 1: Dibujo y desarrollo del vaso encontrado en la mano izquierda del personaje principal de la Tumba Este de la Huaca Loro (Temporada 1991-92). Dibujo de César Samillán.

adelante), que no presenta diseño alguno. Por último, se trata de vasos especiales, que no forman parte de las ofrendas que acompañan al difunto, sino que realmente son los vasos usados por el ancestro o por la divinidad para beber o en los que, quizá, ya haya bebido. Esto les confiere un carácter sagrado, no sólo utilitario, que les diferencia del resto.

De los cinco vasos analizados, cuatro fueron encontradas en una mano de personajes de élite excavados en diferentes lugares de la Huaca Loro y solamente una en un entierro excavado en la Huaca Las Ventanas, ubicada a pocos metros de la anterior.

\subsection{Vaso del personaje principal de la Tumba Este en la Huaca Loro}

La primera tumba importante de un personaje de élite sicán fue excavada entre los años 1991-92, en la llamada Huaca Loro o Huaca Oro (Shimada 1995: 55). El equipo del PAS, dirigido por el Dr. Shimada, descubrió en el sector Este de la huaca una tumba ubicada a $11 \mathrm{~m}$ de profundidad. En ella se situaba una cámara funeraria en donde se desenterraron $1.250 \mathrm{~kg}$ de piezas de oro, plata y diversos ornamentos (Shimada 1995; Shimada et al. 2000). La cámara funeraria, de 3 x 3 m, tenía en las cuatro paredes siete nichos que contenían cinco individuos: un adulto masculino, dos adultos femeninos y dos jóvenes. Los bienes funerarios fueron colocados superpuestos en capas sobre, alrededor y debajo del cuerpo de un personaje masculino, de unos 40 a 50 años de edad, colocado en el centro de una esterilla cuadrada. Acompañaban al personaje gran cantidad de objetos metálicos, chaquiras, Spondylus, Conus, etc. Entre estos objetos llama la atención un par de guantes ceremoniales desproporcionados en tamaño (1 m de largo) y muy mal conservados, los cuales flanqueaban el cuerpo del personaje principal y terminaban en unas manos, también desproporcionadas, de las cuales la izquierda sujetaba un vaso-sonaja de metal mirando al este (Figura 1).

El vaso está hecho en dos partes: la superior con diseños de figuras y la inferior que forma la sonaja propiamente. La primera está manufacturada con una lámina de oro repujada que consta de una banda o registro horizontal, la cual ocupa casi toda 
la superficie del vaso y muestra tres personajes frontales de pie, con cuerpo frontal y piernas de perfil, en diseño corrido. Dichas figuras están enmarcadas en la parte superior e inferior por un diseño repujado en forma de cordón muy delgado. En la cabeza llevan un adorno de forma semicircular, de tipo casquete, con adornos de plumas. Todas ellas sujetan un bastón o báculo en cada mano que termina en una punta triangular o de «diamante». Los tres rostros portan la típica máscara sicán, es decir, con los convencionales ojos almendrados, nariz aguileña, comisuras marcadas y orejeras. La parte inferior, la base del vaso, es la sonaja propiamente dicha; está hecha de otra lámina, en este caso de plata y, desgraciadamente, en muy mal estado de conservación, con diseños recortados formando cuadrados en donde van pequeñas bolitas internas que al agitar el vaso producen el sonido. Esta sección es muy parecida, tanto en la manufactura como en la forma geométrica del diseño, al vaso de una anciana encontrada en el fardo de la Huaca de Las Ventanas a la que haremos referencia posteriormente.

\subsection{Vaso del personaje principal de la Tumba Oeste en la Huaca Loro}

En 1995 el Dr. Shimada y su equipo decidieron excavar el sector Oeste de Huaca Loro, encontrando una tumba que se denominó Tumba Oeste. Ésta estaba simétricamente ubicada en relación a la Tumba Este y tiene grandes dimensiones, incluyendo más de 25 entierros, de los cuales uno era el personaje principal. A unos $15 \mathrm{~m}$ de profundidad, una enorme antecámara con los restos de 24 mujeres sacrificadas indicaba que unos metros más abajo se enterraba un alto dignatario. El personaje principal estaba situado en una cámara central dentro de la antecámara, a unos $3 \mathrm{~m}$ de profundidad; era un hombre de unos 40 años de edad, con una herida punzante grave -posiblemente mortal- en la pelvis, y estaba colocado en el centro de un piso de tapetes alineados, en posición sedente con las piernas cruzadas (Shimada et al. 2000). Como el personaje de la Tumba Este, el de la Tumba Oeste estaba acompañado por una gran variedad de bienes funerarios y ofrendas (Figura 2a) y también tenía dispuestos - flanqueando asimismo su cuerpo- unos falsos guantes largos hechos quizás de madera de balsa, de aproximadamente un metro de largo, y, en este caso, el vaso estaba en la mano derecha (Figura 2b).

Este vaso, aunque parecido al encontrado en la Tumba Este, muestra variaciones en forma e iconografía. Está compuesto por una sola lámina de tumbaga (oro/plata/ cobre) que lleva repujada una tira corrida de seis figuras completas frontales con casquete semicircular adornado con plumas, las cuales sujetan un bastón o báculo en cada mano, también terminando en forma triangular o de diamante (Figura 3). Como en el vaso anterior, el cuerpo de las figuras está representado en posición frontal y piernas y pies de perfil y lleva una camiseta o uncu que llega a la rodilla. El rostro enmascarado tiene la forma de la típica máscara sicán, con ojos almendrados, nariz aguileña, comisuras marcadas y orejeras. La sección o banda donde están las figuras está enmarcada por un adorno repujado de círculos que lleva encima una línea en zigzag en la que el vértice de cada triángulo coincide con un círculo. Carece de una base calada como la del de la Tumba Este y el mal estado de conservación nos dificulta determinar si le faltaba esta sección que haría de sonaja o realmente nunca la tuvo. 

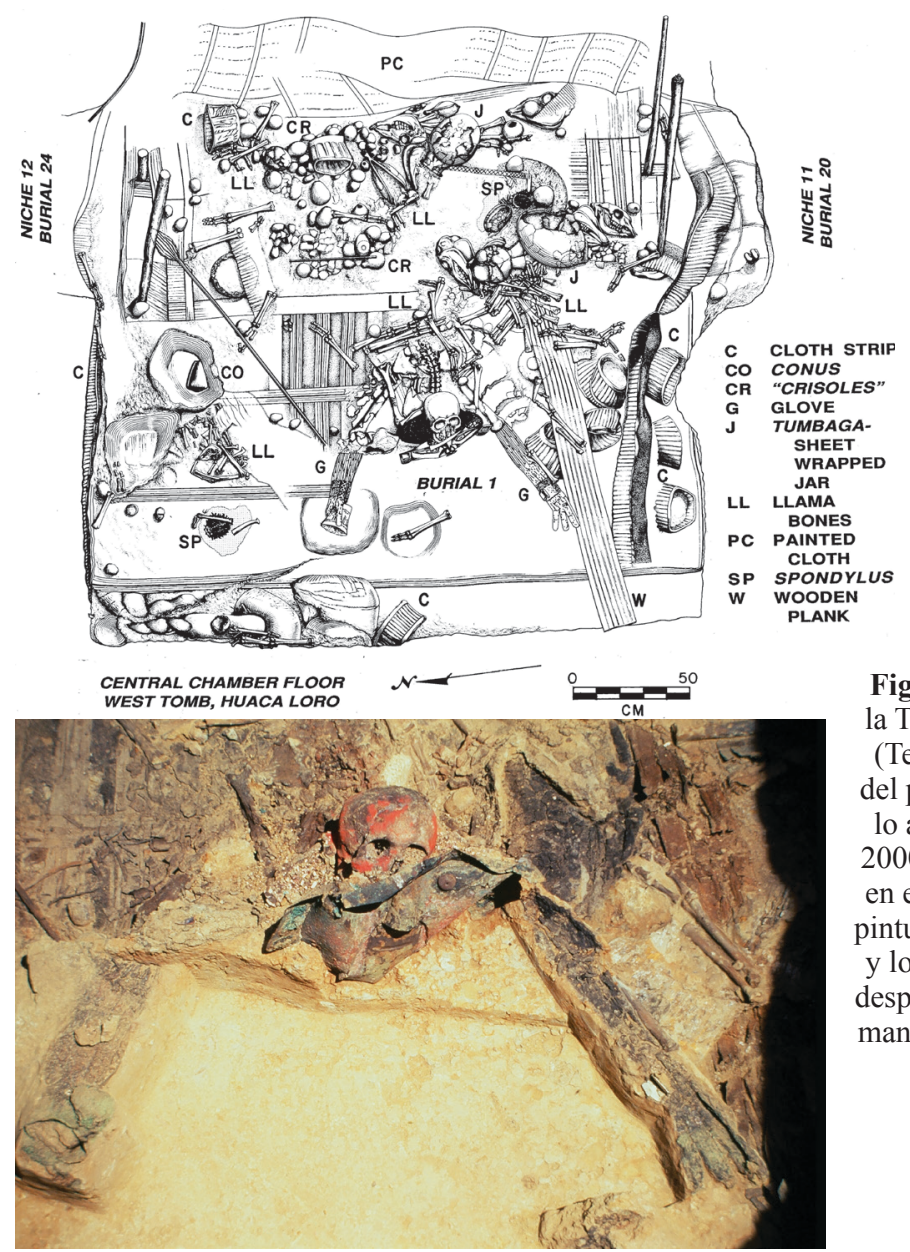

Figura 2: Personaje principal de la Tumba Oeste de la Huaca Loro (Temporada 1995-96); a) dibujo del personaje con las ofrendas que lo acompañaban (Shimada et al. 2000: 45); b) detalle del personaje en el que se aprecia el cráneo con pintura roja de cinabrio, la máscara y los dos falsos brazos de tamaño desproporcionado con el vaso en la mano derecha (fotografía de Izumi Shimada).
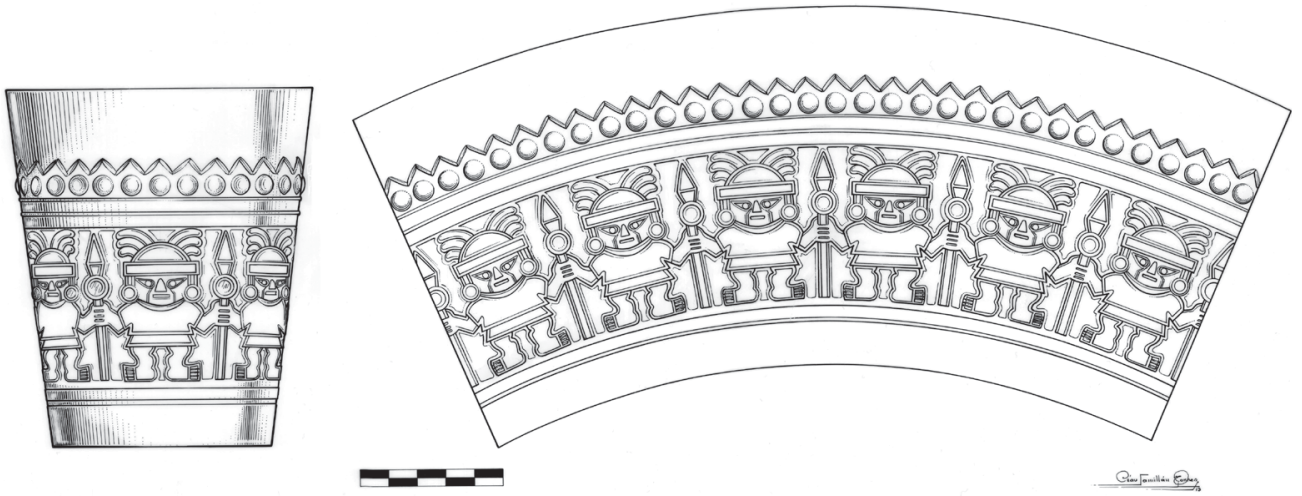

Figura 3: Dibujo y desarrollo del vaso encontrado en la mano derecha del personaje principal de la Tumba Oeste de la Huaca Loro (Temporada 1995-96). Dibujo de César Samillán. 
Si bien es cierto que existen similitudes entre los objetos metálicos encontrados en la Tumba Este y en la Tumba Oeste, también hay grandes diferencias tanto en la calidad de las materias primas como en el tipo de aleaciones empleadas en los objetos metálicos. Así, en los objetos metálicos de la Tumba Oeste la aleación utilizada en la mayoría es la tumbaga, mientras que en la Tumba Este son de aleación de oro con alto contenido de oro y plata. También hay diferencias en las materias primas empleadas, siendo las de la Tumba Oeste de menor calidad. Por otra parte, la finura y especialización del trabajo orfebre en la Tumba Este no es comparable con el de la Tumba Oeste. Pero, a pesar de ello, los objetos metálicos encontrados en esta última son de gran belleza e ingenio técnico.

\subsection{Vaso del personaje principal de la Tumba 1 (2006) en la Huaca Loro}

En los trabajos de campo del año 2006 el Dr. Shimada excavó y localizó más de 30 entierros y tumbas intactas de diferentes tamaños, formas, orientación y momentos dentro del periodo del Sicán Medio (900-110 d.C.) que se encontraban ubicadas en los alrededores del templo-mausoleo de Huaca Loro (Matsumoto 2010). El único vaso encontrado en estos contextos rituales se halló en la llamada Tumba 1 (Figura 4a), que perteneció a una mujer de unos 20 años de edad, cuyo fardo se encontró en una cámara funeraria en forma de pozo, de unos 3,6 m de largo por 3 de ancho y 5 de profundidad. Contaba con tres nichos y numerosos bienes funerarios, así como con un acompañante adulto femenino. Parece que se enterraron dos infantes en la boca de la tumba en el momento de sellarla.

El fardo portaba una corona de cobre y plata. El cuerpo se encontraba sentado con las piernas cruzadas y acompañado por varias ofrendas. Entre las piezas de metal se encontraron dos tumis simples (Figura 4b), de aleación de cobre con plata, y un vaso de cobre y plata con pedestal, posiblemente sonaja, que es el que se analiza en este trabajo. Lo interesante de este entierro es que el vaso se encontró junto a dos tumis de
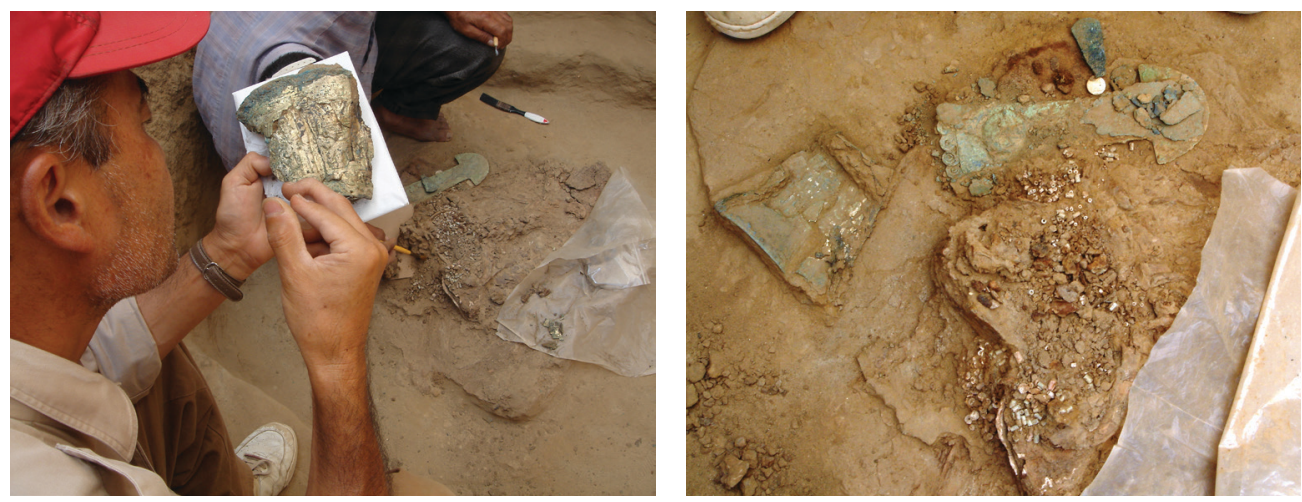

Figura 4: Personaje principal de la Tumba 1 de la Huaca Loro (Temporada 2006):

a) el Dr. Shimada limpiando el vaso encontrado en la mano del personaje; b) tumi o cuchillo ceremonial hallado junto al vaso. (Fotografías de Paloma Carcedo). 


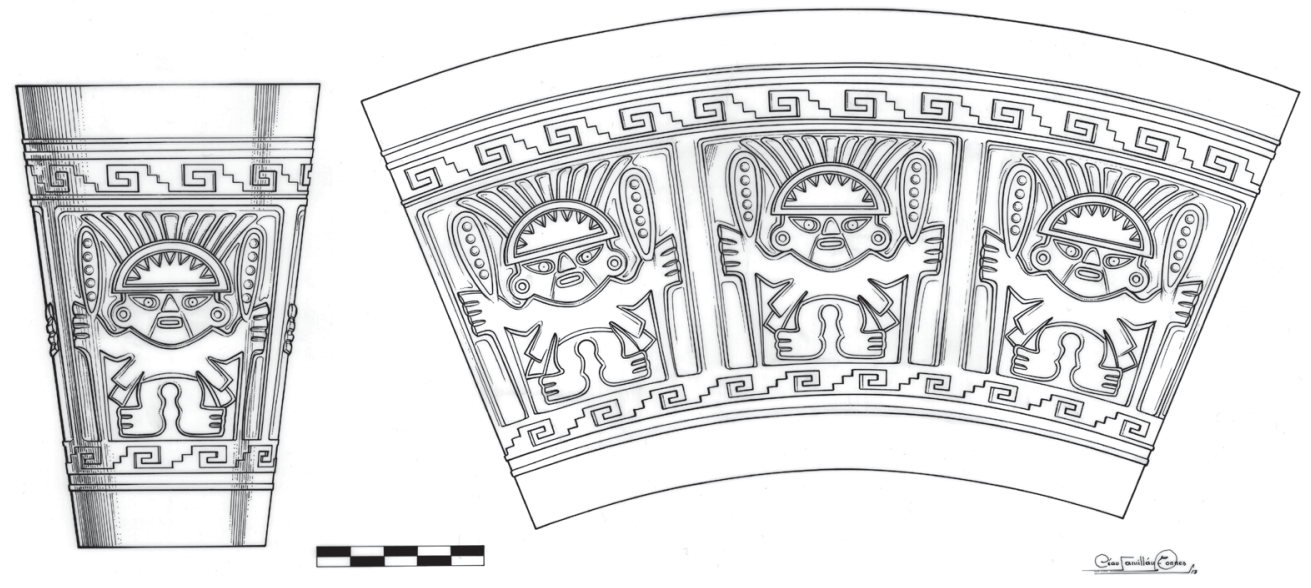

Figura 5: Dibujo y desarrollo del vaso encontrado en la mano del personaje principal de la Tumba 1 de la Huaca Loro (Temporada 2006). Dibujo de César Samillán.

tumbaga con representaciones de la deidad sicán, que han sido los primeros y únicos tumis encontrados in situ con este tipo de iconografía. Además de este entierro, se hallaron al menos cinco tumbas menores (que contenían individuos masculinos y femeninos y un conjunto de ofrendas de bienes suntuarios) colocadas alrededor de la primera tumba en un período de 50 a 100 años posterior a su entierro, lo que sugiere una duradera memoria social de esta mujer de élite.

El vaso que portaba el personaje se encontró en muy malas condiciones y está hecho de una lámina de tumbaga (cobre/plata/oro) embutida y repujada. El cuerpo se divide en tres franjas o campos (Figura 5). La franja central, que ocupa tres cuartas partes de la superficie, está compuesta por una tira de tres figuras frontales y cada una sujeta en sus manos un bastón. Como en los casos anteriores, el cuerpo está en posición frontal y las piernas y pies de perfil. En este caso, parece que lleva puesto algún tipo de camiseta o uncu que termina en unas prolongaciones que salen de ambos lados de la cintura. La cabeza de cada una de las figuras está cubierta por un casquete semicircular que termina en un adorno de plumas y lleva en su filo superior un ornamento dentado que sigue su forma semicircular externa. El rostro porta la típica máscara del Sicán Medio de ojos almendrados, nariz aguileña y comisuras marcadas, así como orejeras. A diferencia de los anteriores vasos, las tres figuras están claramente separadas y «encajadas» en tres campos cuadrangulares que enmarcan a cada una de ellas, ocupándolos por completo y dando lugar a cierta «ley del marco», como si quisieran aludir a un espacio físico que las separa. Encuadrando la banda horizontal con las figuras se disponen, en la parte superior e inferior, dos estrechos campos con diseños de olas escalonadas en direcciones contrapuestas; el superior hacia la derecha y el inferior hacia la izquierda. Cada figura sujeta un bastón en cada mano. Estos son diferentes a los que portan las figuras de los vasos anteriores, ya que, en este caso, la parte superior del bastón termina en forma oblonga y lleva en el centro una fila con cinco diseños circulares. 


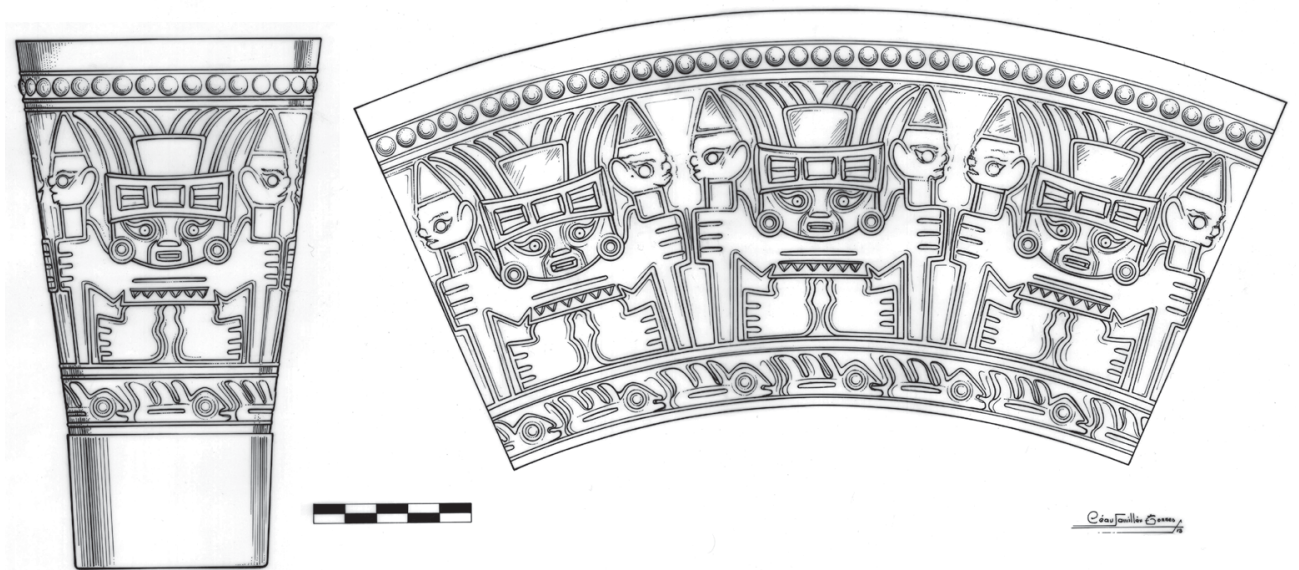

Figura 6: Dibujo y desarrollo del vaso encontrado en la mano del personaje de la tumba de la Huaca Loro excavada en 2008. Dibujo de César Samillán.

\subsection{Vaso del personaje principal de la tumba excavada en 2008 en la Huaca Loro}

En la temporada de campo de 2008, el Dr. Izumi Shimada y su equipo continuaron las investigaciones en el perímetro de la Huaca Loro, esta vez en la esquina noreste. En esta temporada se excavaron ocho áreas con otros tantos contextos funerarios, de los cuales tres estaban cercanos al lado noreste del Templo de Huaca Loro (Matsumoto 2010). De estos tres contextos, dos de las tumbas se encontraron parcialmente saqueadas por bulldozer en los años 1968-69, pero la tercera estaba intacta. Esta tumba, situada en el nicho sur, tenía el entierro de un personaje adulto sentado con las piernas flexionadas cruzadas, el cual llevaba un pesado tocado compuesto por un esqueleto o estructura de metal que caía por la parte frontal y la espalda, un pectoral muy elaborado de chaquiras de conchas moradas y blancas, una máscara dorada, una corona de cobre y plata, un largo tumi simple de tumbaga sin decoración en la mano izquierda ${ }^{3}$, un par de falsos guantes y un vaso-sonaja de cobre dorado en la mano derecha. Acompañaba al entierro una cerámica rojiza que representaba una figura de una mujer con tembetá ${ }^{4}$ que parece estar sentada libando. El uso del tembetá es típico de la población de etnia tallán, ubicada al norte de Batán Grande, cerca de Piura. Quizás ello haga alusión a que el entierro pertenecía a un personaje de esta etnia.

Este vaso presenta una iconografía parecida a los anteriores pero con detalles sustancialmente diferentes (Figura 6). Está hecho también de una lámina de tumbaga (plata/oro/cobre) y, en este caso, con una base elaborada de forma independiente y unida al cuerpo principal mediante presión y quizás calor. El cuerpo principal del

3 Los trabajos de excavación de la Temporada 2008 todavía no han sido publicados por el Dr. Shimada. La autora se limitará a analizar el único vaso encontrado junto a un entierro en esta temporada. En futuras publicaciones se facilitarán más datos.

${ }^{4}$ Pequeño adorno de metal de forma cilíndrica que los indígenas se insertaban en el labio inferior previamente perforado. 
vaso presenta tres registros o bandas horizontales repujadas. El registro central presenta un diseño de tres figuras sujetando un bastón en cada mano. Dichas figuras están enmarcadas por una banda superior con diseños circulares o «perlas» y una banda inferior con diseños de aves orientadas en una dirección. En este caso, los tres personajes no presentan un casquete semicircular sino un tocado trapezoidal en forma de «T» invertida con diseños en la sección rectangular rematando en un adorno de plumas. El cuerpo de los personajes, como en los anteriores casos, está representado de forma frontal con las piernas y pies de perfil. Las figuras llevan la típica máscara sicán de ojos almendrados, nariz aguileña y comisuras marcadas, así como orejeras y un uncu o camiseta que cubre el cuerpo hasta la rodilla. En este caso, los bastones terminan con la forma del perfil de una cara sicán con un tocado en forma triangular. El diseño de estos báculos se tratará más adelante.

\subsection{Vaso del personaje principal -la Anciana- de la tumba excavada en la Huaca Las Ventanas (2006)}

En noviembre del año 2006, en la Huaca Las Ventanas, cerca de la Huaca Loro, se encontró un formidable entierro, esta vez por parte del Dr. Carlos Elera, director del Museo Nacional Sicán, y su equipo. Situado en la esquina sur-este del volumen piramidal de la Huaca Las Ventanas, está compuesto por un rico fardo y otro entierro más sencillo que formaba parte de un contexto funerario más complejo (Elera, comunicación personal) $)^{5}$. Los estudios preliminares han dado como resultado que el entierro corresponde a una mujer anciana que debió de ser tejedora o estar relacionada con este trabajo y que, por el rico ajuar que presenta, debió de pertenecer a la élite de Sicán ${ }^{6}$. El cuerpo y el rostro se orientaban hacia el oeste, estaba sentada en posición de flor de loto y portaba varios collares de chaquiras y dos pequeños tumis de cobre en su lado izquierdo. El fardo estaba compuesto por varias capas de tela que formaban su volumen y en la última capa se cosieron piezas de metal de forma cuadrangular. Las principales piezas de metal que acompañaban al fardo fueron la máscara y la corona, llevando además alrededor cuatro paquetes de ofrendas de metal de oro, plata, cobre y tumbaga, todas dobladas y aplastadas. Entre los objetos aplastados se encuentran vasos de doble pico de aleación de tumbaga, posiblemente cobre con plata, sin diseños. Acompañan al fardo dos brazos de madera falsos hechos con madera de balsa y cubiertos de láminas de cobre dorado, los cuales sujetaban en la mano derecha un vaso-sonaja de oro y plata, como ofreciendo bebida, y dos tumis simples en la izquierda. Sólo le acompañaba una cerámica con la forma típica del «Huaco Rey». Aunque la conservación de la máscara y la corona no son muy buenas, es fácil reconocer la típica máscara sicán del periodo Clásico, la cual mantiene la pintura de cinabrio y los adornos de ojos, nariz y orejeras.

\footnotetext{
5 Uno de los problemas que nos encontramos es la ausencia de publicaciones sobre hallazgos arqueológicos realizados en el área de Pómac en los últimos cinco años. Si bien entre 1991-92 y 1993-95 encontramos abundante información, tenemos pocos artículos publicados sobre los hallazgos del 2006 al 2012; por eso, en algunos casos nos remitimos a comunicaciones personales o a información publicada en los periódicos locales.

6 El dibujo publicado por el diario peruano El Comercio el 27 de noviembre del 2006 es la única información que se tiene en prensa sobre este fardo.
} 

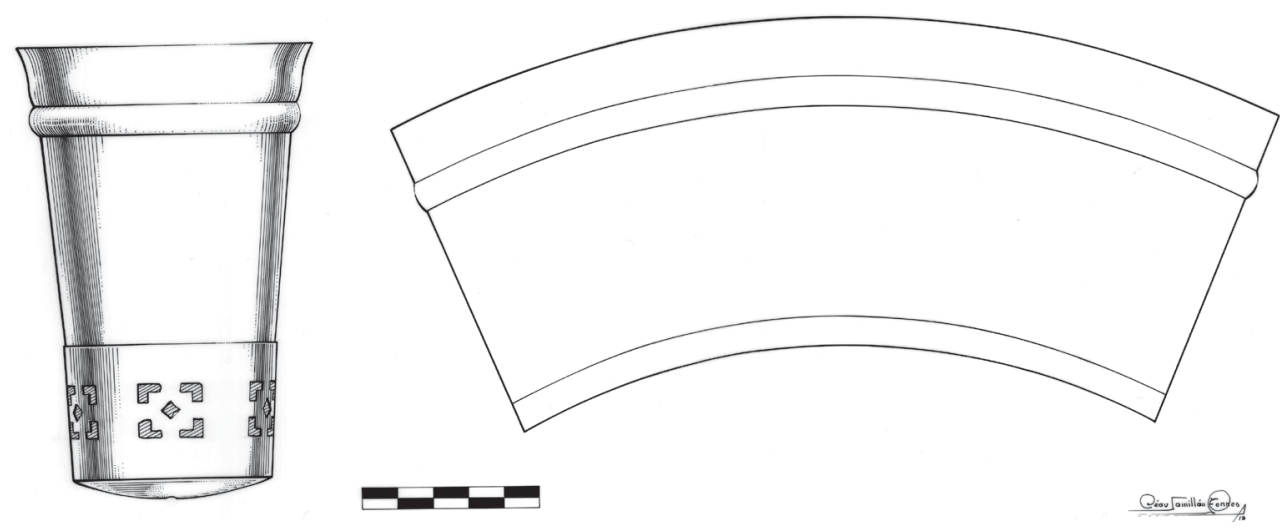

Figura 7: Dibujo y desarrollo del vaso encontrado en la mano derecha del personaje principal -la Anciana- de la tumba de la Huaca Las Ventanas (Temporada 2006). Dibujo de César Samillán.

El vaso-sonaja de la denominada «Anciana» tiene forma de kero alargado (Figura 7) y se manufacturó en dos partes, del mismo modo que los tres vasos-sonaja ya descritos. La parte superior, hecha en cobre dorado, no presenta diseños repujados en el cuerpo central, como los vasos anteriores, pero lleva una banda tallada en forma de cordón a lo largo de toda la zona superior. Este tipo de decoración lo hemos visto en otros vasos de oro de la misma cultura que se encuentran en el Museo del Oro del Perú (Carcedo 2012a y b) (véase, por ejemplo, el de la Figura 8). La parte inferior, hecha de una lámina encajada por presión, y quizás calor, al cuerpo del vaso, presenta un diseño calado de forma cuadrangular que hace las veces de sonaja. Este diseño es muy parecido al descrito en el vaso-sonaja encontrado en el personaje principal de la Tumba Este de la Huaca Loro.

A mediados de marzo de 2010, a unos 1.500 metros al oeste de la Tumba Este de Huaca Loro, el Dr. Carlos Elera y su equipo encontraron un fardo que contenía los restos de un personaje de élite del Sicán Medio. El personaje, como los demás descritos, estaba enterrado en posición de flor de loto y en la parte superior del fardo había una máscara típica con pintura roja de cinabrio muy bien conservada y una corona en muy mal estado. Como en los anteriores casos, a ambos lados del fardo había dos secciones alargadas a modo de brazos artificiales que sujetaban un cuchillo ceremonial en una mano y en la otra un vaso de metal, posiblemente aleación de oro y plata, cubierto por un trozo de tela de algodón nativo, el cual aún no ha podido ser dibujado, razón por la que no se incluye en el presente estudio.

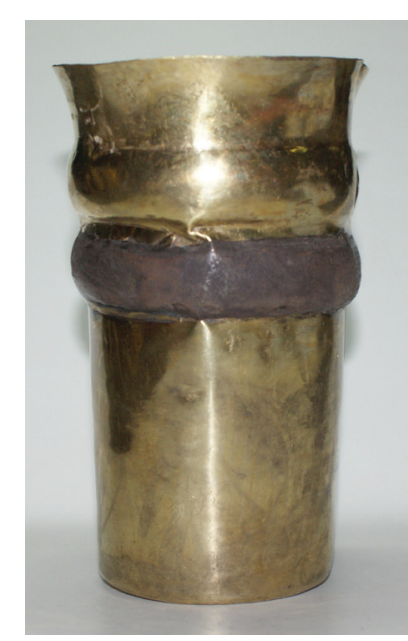

Figura 8: Vaso de oro de la cultura Sicán, Museo del Oro del Perú (M-1417). Fotografía de Paloma Carcedo. 


\section{Similitudes y diferencias entre los cinco vasos}

En toda superficie en la que se representan imágenes existe una lectura de éstas que hay que entender o saber interpretar. Entre otras cosas porque hay que averiguar cuál era la función social y cultural que cumplían. En el caso de los cuatro vasos mostrados, no solamente son importantes las representaciones de las figuras sino también los diseños que van asociados a éstas y que seguramente guardan un significado estrechamente ligado. Debemos interpretar, por lo tanto, el significado no sólo de las figuras aisladas sino de la totalidad del espacio y de los elementos alrededor de ellas, ya que el conjunto de la representación es lo que nos va a transmitir los conceptos que debemos «saber leer». Los vasos del Sicán Medio, etapa a la cual corresponden los cinco vasos, se convierten no sólo en objetos funcionales, hechos para beber por el hombre y/o los dioses, sino además en vasos sagrados en cuyas superficies se expresan conceptos concretos. Como vemos, la sencillez y simplicidad de los diseños expresan una sensibilidad o gusto artístico diferente a sus predecesores, los moches, con diseños iconográficos más «arcaicos», más simples y conceptuales. Estos diseños claros, directos y sencillos cambiarían notablemente al final del Sicán Tardío y luego en el periodo Chimú, donde una especie de horror vacui inunda las superficies de los objetos metálicos. El arte conceptual del Sicán Medio en los objetos de metal es único y determinante de este periodo.

\subsection{Tocados y bastones que portan las figuras}

Cuatro de los cinco vasos presentan en su cuerpo central diseños de personajes típicos de la iconografía sicán, es decir: personajes de pie, con los brazos abiertos sujetando báculos en sus manos, con la cabeza y busto frontal pero con piernas y pies de perfil. Todos llevan la típica máscara y orejeras. De los cuatro vasos con figuras, en tres de ellos el tocado que ostentan tiene forma de casquete semicircular y sólo en uno -el correspondiente a la tumba excavada en 2008 en la Huaca Loro- las figuras llevan un adorno trapezoidal frontal con un adorno alargado en forma de «T» invertida, aunque en los cuatro casos el tocado termina en un adorno de plumas.

Figuras con casquetes semicirculares y trapezoidales son usuales en la iconografía, encontrándose tanto en objetos metálicos -ya sean placas o en bulto redondocomo en tumis, telas pintadas, pintura mural, diseños de vasos, etc. Lo curioso, en el mencionado caso de las figuras rematadas con un tocado trapezoidal, es que el personaje que portaba el vaso lleva un tocado metálico en forma de corona con una estructura nunca antes vista en un fardo del Sicán Medio. Ésta consiste en unas tiras metálicas que se cruzan en la parte superior de la cabeza y que caen por la espalda. Las malas condiciones de conservación del tocado no permiten, por ahora, determinar bien su forma, pero, definitivamente, es muy diferente a la estructura de corona que portan los demás personajes que llevan el vaso en la mano. Este punto es interesante, porque podemos asociar este vaso, en el cual se representan figuras con tocados trapezoidales, con un personaje que lleva un tocado completamente diferente a los de los que portan los otros vasos. Por otro lado, el bastón que llevan las figuras remata en 

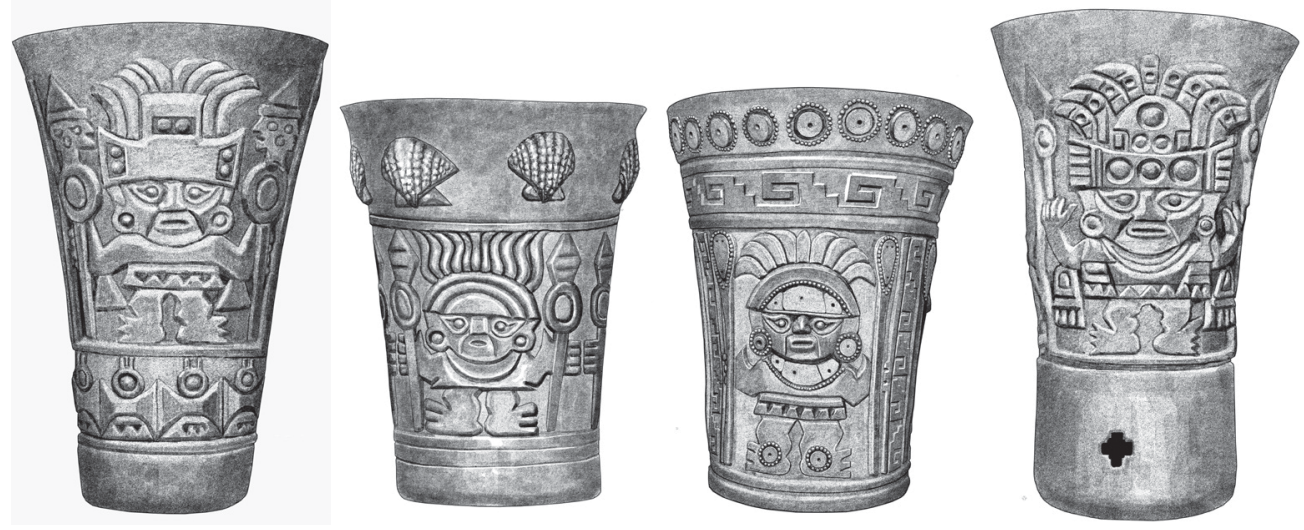

Figura 9: Cuatro vasos de oro de la cultura Sicán: a) M-1362;

b) colección privada; c) M-1463; d) M-1364. («M»: Museo del Oro del Perú)

un rostro de perfil típico en la iconografía sicán, el cual luce un adorno triangular en la cabeza. Este diseño tampoco lo vemos en ninguno de los bastones representados en los otros tres vasos, pero sí lo hemos encontrado en vasos-sonaja de oro que la autora ha estudiado y que se encuentran en el Museo del Oro del Perú (Carcedo 2012a y b) y en algunos personajes que conforman el espaldar de la Litera Sicán, que se encuentra también en el mismo museo y sobre el cual la autora publicó hace tiempo un estudio (Carcedo 1989). Llama la atención que las figuras representadas en uno de los vasos del Museo del Oro (Figura 9a) no sólo coinciden con las del vaso de la tumba excavada en 2008 en la forma del tocado, sino que además la banda inferior que bordea ambos vasos representa elementos relacionados con iconos del mar, aves en uno y peces en el otro, siguiendo un patrón que se observa también en las estructuras del espaldar de la Litera Sicán, donde se representan olas (Figura 10).

Del estudio de los vasos mencionados del Museo del Oro, las figuras de la litera y el vaso de la tumba del 2008 podemos inferir varias características comunes: 1) son sonajas; 2) las figuras llevan un tocado trapezoidal; 3) las figuras portan en ambas manos cetros o báculos que terminan en rostros de perfil con un adorno triangular encima; 4) las figuras están enmarcadas por una banda de aves o peces marinos u olas. ¿Guardan alguna relación estas coincidencias? ¿Nos indicarán que estamos hablando de un mismo grupo étnico o de linaje? Estudios posteriores tendrán que profundizar en este tema añadiendo información que permita obtener conclusiones más firmes, pero si fuera así, tendríamos una clara relación entre el personaje que lleva el vaso y un grupo determinado, ya sea de linaje o étnico, que honra a un mismo ancestro.

En las figuras de los otros tres vasos analizados aquí, a pesar de que todos lucen tocados similares de casquetes en forma de semicírculo, los bastones que portan son diferentes y ninguno termina con la forma del perfil de un rostro. Mientras que los báculos del vaso de la Tumba Este terminan en punta de «diamante», en las figuras de la Tumba Oeste, además de terminar en esa forma, el bastón lleva un adorno circular debajo, a la altura de las manos, como las figuras de otro vaso estudiado por la autora (Figura 9b). Por el contrario, los báculos de las figuras del vaso de la Huaca Loro ha- 


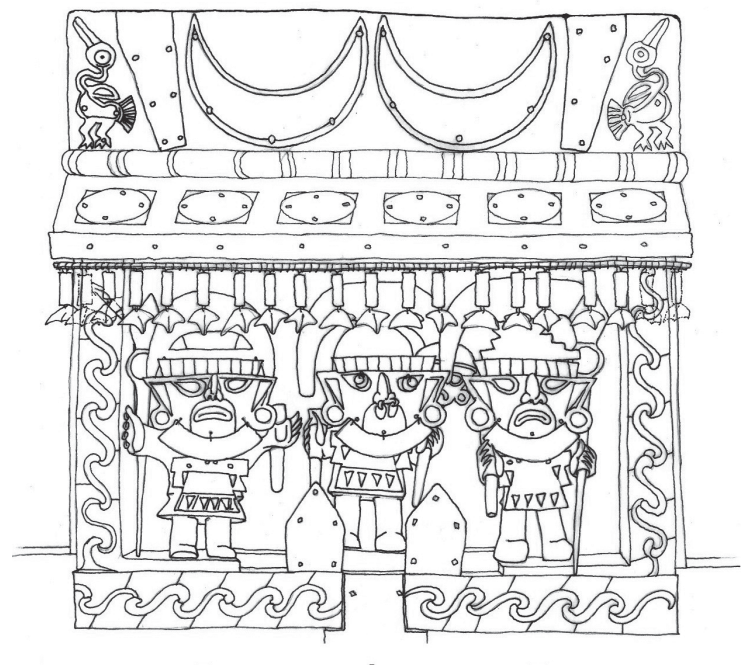

5
6
7
Figura 10: Templete B de la Litera del Museo del Oro del Perú; la figura central (la $\left.n^{\circ} 6\right)$ tiene máscara completa, báculo con rostro y vaso, mientras que las laterales (5 y 7) portan báculo con punta de diamante y vaso. Dibujo de Paloma Carcedo.

llada en 2006 terminan en forma oval con cinco adornos circulares en el centro, como los bastones que portan algunas figuras de vasos de oro estudiados por la autora en el Museo del Oro (Figura 9c).

\subsection{Los elementos geométricos asociados: diseños circulares, en triángulo y la ola escalonada}

En los cuatro vasos con figuras aquí analizados, éstas se encuentran asociadas con diseños geométricos. En tres de ellos los diseños van repujados en la misma superficie que las figuras, mientras que en el vaso de la Tumba Este el diseño calado en forma de cuadrado no está en la misma superficie, sino en la base plateada que forma la sonaja.

En el vaso de la Tumba Oeste, los diseños de las figuras están enmarcados por una banda superior con diseños de círculos y sobre éstos se dispone una banda en forma de zigzag. El vaso de la tumba excavada en 2008 lleva también sobre las figuras una banda con adornos circulares, pero, en vez del adorno en zigzag, añade una banda inferior con peces de perfil mirando hacia el frente. Por otro lado, mientras que en tres vasos las figuras van dispuestas en bandas seguidas, solamente en el de la tumba excavada en 2006 van adaptadas a un marco cuadrado y, en este caso, delimitadas por una banda superior e inferior con diseños de olas escalonadas en direcciones contrapuestas, la superior hacia la izquierda y la inferior hacia la derecha.

Si comparamos este último vaso con el vaso de oro de la Figura 9c, observamos que en ambos las figuras sujetan bastones que terminan en una forma oval similar y van enmarcadas por franjas de diseños de olas escalonadas. ¿Qué nos está indicando esto? Sabemos que el vaso del Museo del Oro -según información procedente del propio Museo- fue encontrado en el área donde se ubica el centro religioso Sicán; ¿serían los báculos un distintivo de un mismo grupo o linaje? En otro lugar (Carcedo 2012b), la autora ha hecho referencia a linajes, deidades y ancestros representados en 
Figura 11: Relieves circulares en la Huaca de la Ola Antropomorfa, Complejo Arqueológico ChotunaChornancap.

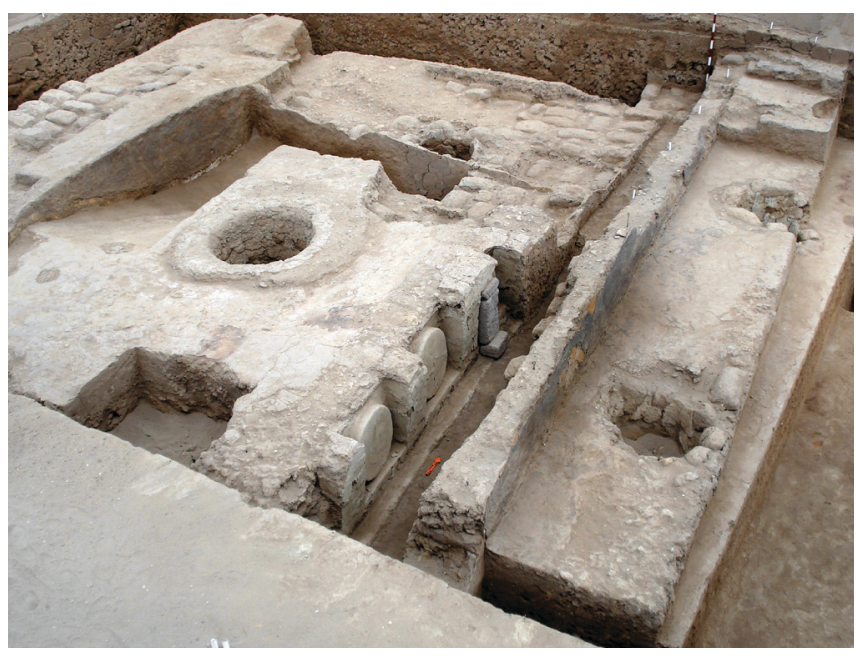

los personajes de la iconografía Sicán, tanto en metal como en cerámica o madera. En ese escrito, como aquí, se analizan no sólo las figuras representadas en los vasos, sino su relación con los elementos iconográficos geométricos que las acompañan. Algunos de estos son los círculos, olas escalonadas y zigzags que vemos representados también entre nuestros cinco vasos. La clave de su interpretación la dieron las estructuras arquitectónicas encontradas en las excavaciones realizadas en el templo conocido como la Huaca de la Ola Antropomorfa, situado $220 \mathrm{~m}$ hacia el norte de la llamada Huaca Chotuna, dentro del Complejo Arqueológico Chotuna-Chornancap, a $10 \mathrm{~km}$ al oeste de la ciudad de Lambayeque (Wester 2010, 2012) ${ }^{7}$. En una de las plataformas perteneciente a la segunda remodelación, Wester y su equipo (2010: 120-121) encontraron en los flancos internos relieves con diseños circulares de $0,50 \mathrm{~m}$ de diámetro, enmarcados en recuadros en forma de hornacinas de 0,60 m de lado (2010: 110, 121 y 139) (Figura 11). Lo interesante de esta iconografía es que los pequeños templos que se sitúan dentro de estas plataformas tienen la misma rampa y diseños circulares que los seis templetes de la mencionada Litera Sicán del Museo del Oro estudiada por la autora (Carcedo 1989: 252 y 253). Si bien Wester no reconstruye el techo del Templo de la Ola en su publicación, posiblemente éste sería como los seis templetes representados en dicha litera.

Llama la atención, en el diseño de olas escalonadas que enmarcan las figuras del vaso del 2006, que discurren en direcciones opuestas. Donnan (1989: 109), que trabajó en el edificio denominado por él Huaca Gloria -la Huaca de los Frisos de Wester (2010: 43-44)-, situado $50 \mathrm{~m}$ al noreste de la pirámide mayor conocida como Huaca Chotuna, encontró en el «patio A» frisos y diseños de peces, aves, olas o volutas que cambian de sentido como el movimiento del mar. Wester (2010: 48), en sus excavaciones en este mismo sitio, reabrió el área del muro que delimita el patio de los frisos,

7 El complejo arqueológico al que nos referimos está formado por las estructuras denominadas Huaca Chotuna, Huaca de los Frisos (antes Huaca Gloria), Huaca Susy y Huaca de los Sacrificios (antes Huaca Norte), y al extremo oeste, a sólo $1 \mathrm{~km}$ de distancia, la Huaca Chornancap. Carlos Wester La Torre -arqueólogo encargado de las excavaciones y, al mismo tiempo, director del Museo Nacional Brüning de Lambayeque- ha denominado a la totalidad del cojunto Complejo Arqueológico Chotuna-Chornancap. 
exponiendo un paramento externo en el lado noroeste que muestra una estructura escalonada que se asocia a peces esquematizados que se desplazan de sur a norte y viceversa. Esta forma de discurrir elementos en diferentes direcciones la vemos en los diseños de olas laterales representadas en las estructuras de la Litera del Museo del Oro, en los diseños escalonados que terminan en una ola del vaso del 2006 y en otros vasos estudiados por la autora (Carcedo 2012a y b). El diseño escalonado que termina en ola es característico en vasos del Sicán Medio; en algunos la ola escalonada delimita bastones con caras de perfil, como los que portan las figuras del vaso del 2008 de Huaca Loro, y en otros delimita diseños de figuras sentadas, con tocado de casquete semicircular que termina en un penacho de plumas y portan un vaso. En ambos casos la ola escalonada discurre en una sola dirección.

Por otro lado, en el vaso del 2008 las figuras van delimitadas por una banda superior con diseños de círculos, como los encontrados en la Huaca de la Ola Antropomorfa, y una inferior con aves marinas o peces esquematizados, como se encuentra en la Huaca Los Frisos y en la maqueta de madera hallada por Uceda (2008) en las excavaciones de la Huaca de La Luna, en el valle de Moche, la cual está sirviendo de mucha ayuda para esclarecer el uso de espacios ceremoniales en las huacas. En esta maqueta, se representa al ancestro ya sacralizado, es decir, a la momia o mallqui con dos bultos o fardos que representan a sus esposas, ofrendas y personajes que cantan y tocan música con antaras o flautas, y un gran cántaro con un personaje con cuchara y otro con vaso, los cuales aluden a que del cántaro se sacaría algún tipo de bebida, posiblemente chicha. Lo interesante es el diseño del espacio y la decoración circundante exterior e interior de dos filas de peces en direcciones opuestas. Estos peces son muy parecidos a los representados en la banda inferior del vaso excavado en el 2008.

El diseño del círculo tiene un importante significado en la cultura Sicán o Lambayeque. Según Narváez (1995: 119) -y coincidimos con su propuesta-, el círculo es la representación del ave mítica y mantiene una estrecha relación con ésta, ya que usualmente aparece asociado con personajes importantes emplumados y con el mar. Otra posibilidad es que haga alusión a la luna, ya que aparece constantemente asociado también a la ola antropomorfa. En la iconografía sicán son reiterativas las figuras que portan objetos en forma circular o medias esferas en las manos. Así, pueden sujetar una esfera completa (como los tumis de oro en que aparece la deidad sentada al estilo «flor de loto»), o medias circunferencias en cada mano (como se observa en figuras de pie con los brazos abiertos) y tanto en cerámica como en objetos metálicos de bulto redondo o tumis. También los círculos aparecen de forma reiterada decorando la cerámica del Sicán Tardío, en las telas pintadas encontradas en tumbas de personajes de élite en Batán Grande y, más recientemente, en el fardo de la sacerdotisa de Chotuna-Chornancap excavado por Wester (2012).

\subsection{Los vasos-sonaja}

De los cinco vasos en estudio, cuatro son sonaja si bien sólo dos han conservado la parte inferior. El vaso encontrado en la Tumba Oeste es muy posible que también fuera sonaja, pero el mal estado de conservación en que se encontró no permite afirmarlo. 
El vaso-sonaja está elaborado en todos los casos en dos partes: la superior, que forma el cuerpo, y la inferior, que forma la sonaja, unidas ambas por presión y posiblemente mediante unión metalúrgica. Si bien la parte inferior que forma la sonaja del vaso de la Tumba Este no se ha conservado bien, sí se ha podido hacer su reconstrucción y sabemos que era de una aleación de cobre y plata, por lo que su color plateado contrastaba con el dorado de la parte superior. La sección inferior que forma la sonaja del vaso de «la Anciana» encontrado en la Huaca de Las Ventanas sí se ha conservado, pero no ha sido limpiada; probablemente su color sea también plateado y diferente al cuerpo superior, que es dorado; en este caso, lleva también un diseño calado en forma de cuadrado con un rombo en el centro y en su interior hay pequeñas bolitas que al agitarse originan el sonido. Esta forma de manufactura de vasos-sonaja en dos partes es habitual en el Sicán Medio. Todos los estudiados por la autora están hechos de igual manera, es decir, en dos partes unidas por presión y, a veces, por un poco de calor. La mayoría tienen un diseño calado en el cuerpo inferior, que puede ser cuadrado o en forma de cruz (véase la Figura 9d), por donde sale el sonido. Algunos, muy pocos, no llevan diseño calado. Hay una categoría de vasos-sonaja que son efigie, es decir, con el diseño de un rostro en alto relieve; estos pueden ser de oro y de plata. La utilización del «color» plateado en la sección inferior del vaso y dorado en la superior debe de hacer alusión a la conocida dualidad, tan presente en la cosmovisión andina, cielo/tierra, hombre/mujer, etc. Habría que analizar más detenidamente este punto.

\subsection{La posición de los vasos en relación con los fardos}

De los cinco vasos, cuatro se han encontrado en la falsa mano derecha del fardo: el de la Tumba Oeste, el de la Anciana del 2006 excavado por Elera, la joven excavada en el 2006 por el Dr. Shimada y el fardo del 2008, también excavado por Shimada, que posiblemente, sea una mujer. El único vaso encontrado en la mano izquierda es el de la Tumba Este de la Temporada 1991-92. Existe una asociación entre sujetar en una mano un vaso y en la otra uno o dos tumis, a excepción de los personajes de la Tumba Este y la Tumba Oeste, que no tienen objetos asociados en estas manos y ambos son hombres, mientras que en los otros tres son mujeres.

\section{Conclusiones}

La forma de kero de los vasos ceremoniales no es nueva en la cultura Sicán y tiene sus antecedentes en culturas anteriores y tan tempranas como las del Formativo (1800-500 a.C.) (Alonso 1990b), continuando en el Horizonte Medio hasta la época Inca (Vetter 2011). No obstante, la mayoría de estos vasos son de piedra, cerámica o madera; se conocen muy pocos casos de vasos de metal en forma de kero en culturas anteriores a la Sicán. Los primeros ejemplos pertenecen a la época de Tiahuanaco ( $c a$. 400 a.C.-1100 d.C.) y son exclusivamente de oro. Uno de ellos procede del entierro de un personaje de élite del ayllu Larrache de San Pedro de Atacama, en el actual territorio de Chile (ca. 400-700 d.C.); según Berenguer (2000: 93), las ofrendas que 
acompañaban a este dignatario incluían «tres vasos de oro del más puro estilo Tiwanaku y un sinnúmero de adornos del mismo metal». Durante los periodos Intermedio Tardío (1000-1400 d.C.) y Horizonte Tardío (1400-1533), también vamos a encontrar vasos de metal, en especial de plata y algunos de oro, en la cultura Chimú y en las de la costa sur. Pero será durante el incanato, y quizás por la abundante información que nos aportan los cronistas, cuando el vaso de metal adquiera un papel primordial; se conocen como aquillas, destinando el nombre de quero o kero al vaso de madera pintado o no (Cummins 2004: 58) usado para los actos rituales y en la estructura simbólica imperial. Cummins (2004: 66) puntualiza que en el léxico del siglo XVI había un vocablo para definir quién manufacturaba los queros, querocamayocs, pero no se encuentra otro análogo para los productores de objetos de metal, las quillas, o de cerámica, «aunque el único artículo que estos tres artesanos [los que manufacturaban vasos de madera, cerámica o metal] producían en común eran los vasos para beber». Es decir, el vaso era un objeto especial y como tal debe de ser entendido.

Aunque, en la cultura Sicán, se han encontrado en excavaciones científicas como ofrendas vasos en forma troncocónica o de kero en diferentes soportes como cerámica y metal, la mayoría de los que se conocen de oro y plata proceden de saqueos y están repartidos por el mundo en colecciones públicas y privadas. Si bien es cierto que se han hallado vasos de metal en entierros de diferentes culturas precolombinas de los Andes Centrales, lo que llama la atención es que solamente sea en esta cultura, y concretamente en algunos entierros del Sicán Medio -no en todos-, donde los personajes de élite sean ellos mismos los que porten en una mano un determinado vaso.

Entre los cinco analizados encontramos bastantes similitudes y muy pocas diferencias; así, cuatro han sido encontrados en fardos o personajes de élite ubicados en la Huaca Loro y sólo uno en la Huaca Las Ventanas; ambas pirámides-mausoleos forman parte del Recinto Ceremonial de las élites del Sicán Medio. Tanto hombres como mujeres podían llevar un vaso en la mano, lo que indica que debió de haber mujeres que cumplían un rol importante dentro de la sociedad.

Existen diversos estudios en los que los investigadores intentan solucionar, desde diferentes puntos de vista, la cuestión de si los personajes de la iconografía Sicán son representaciones de la propia divinidad o su alter ego, personajes de élite enmascarados y si se estaban representando linajes, grupos étnicos o ancestros. Un estudio sistemático realizado por la autora (Carcedo 2012b) de figuras enmascaradas sicán que aparecen en diferentes soportes, en especial en los vasos de oro, concluye que no podemos interpretar que este tipo de personaje esté siempre representado a la deidad o al personaje mitológico Naylamp. Más bien se revela que no todos los personajes representados son iguales y que se diferencian por sus atributos, aunque todos porten la máscara y ésta se represente en todos de forma casi invariable. Ello puede indicar que estén representando diferentes linajes o grupos que mantuvieron de alguna manera cierto poder político y religioso. Shimada y sus colegas (2004) han determinado que algunos de los montículos principales y más grandes de la capital del Sicán Medio -las huacas Loro, Las Ventanas, La Merced, Lercanlech, El Corte y Sontillo-, fueron el escenario en donde diferentes linajes celebraban los rituales a los ancestros.

Ayuda a esta conclusión el que, en los entierros excavados en las últimas décadas por el PAS de personajes de la élite del Sicán Medio, el fardo del personaje principal 
siempre porta una máscara característica, sujeta al fardo, lleva corona, guantes falsos de madera desproporcionadamente alargados y cubiertos por láminas de metal dorado. Los individuos están sentados en posición flor de loto y en las falsas manos llevan algún objeto, por lo general un vaso o un tumi más o menos decorado. Varios autores interpretamos que el personaje, una vez muere y viaja a otro mundo, se convierte en ancestro del linaje, y por lo tanto, con derecho a llevar la máscara de la deidad y a que le guarden culto y honren con ceremonias y rituales, por el bien de la comunidad y de la perpetuidad del propio linaje.

En otro estudio, la autora (Carcedo 2012b) ha identificado algunos objetos de metal encontrados como ofrendas en las excavaciones de tumbas de élite del Sicán Medio con atributos representados en personajes de «Huacos Rey», la llamada deidad Sicán. Esto nos lleva a pensar que la representación de la deidad en algunos casos no es abstracta, como debería de ser la de una deidad, sino que, de alguna manera, se está representando algún personaje que usó ese tocado en vida o al que se le fabricó para su muerte y conversión en ancestro. Es decir, «el huaco o vaso Rey» posiblemente era «diseñado» en vida del difunto. Esta idea nos recuerda a los guauquis incaicos ${ }^{8}$, ídolos o «estatuas» que poseían características propias que los diferenciaban de cualquier otro ídolo u objeto de veneración, y que cada Inca elegía para que lo acompañara en la tumba y representara después de muerto, no sólo a él, sino a todo su grupo de parentesco (Alonso 1990a: 93 y 95). De esta manera el guauqui y el mallqui o bulto del difunto mantienen una estrecha relación y, aun desapareciendo el mallqui, el guauqui puede ocupar su lugar.

Si esta interpretación es correcta, podemos pensar que las figuras representadas en los vasos que lleva el personaje de un fardo, como los que se han expuesto aquí, más que a la deidad Sicán parecen hacer alusión a algún tipo de linaje, como se ha visto en otros vasos y soportes iconográficos. Los elementos que acompañan a las figuras -círculos, olas escalonadas, peces y zigzags- son una clara alusión a sitios ceremoniales -templos o recintos rituales específicos-, como se ha podido estudiar en la Huaca de la Ola Antropomorfa de Chotuna-Chornancap y como se refleja en la maqueta encontrada por Uceda en la Huaca de La Luna. Al ser estos cinco vasos los únicos referentes de «vasos para la otra vida», resulta muy difícil establecer su relación con otros vasos de oro en los que aparecen las mismas figuras, pero de cuyo contexto no tenemos suficiente información por el hecho de no proceder de investigaciones científicas.

Por otro lado, llama la atención que, en periodos anteriores y posteriores al Sicán Medio (Shimada 1990), no se hayan encontrado entierros en que el personaje principal lleve en la mano un vaso. Podemos pensar que para los sicanes de esta época era muy importante entrar al otro mundo brindando con la divinidad o con el ancestro, pero sabemos también por los cronistas que era muy importante en los rituales beber con dos vasos como acto de reciprocidad. Con uno de ellos, el de la derecha, brindaba el dios sol -y una vez terminado el brindis derramaba la chicha en un tinajón de oro del cual salía un caño que iba hasta el templo del sol-y con el izquierdo bebía el Inca

8 Guauquis: ídolo asociado al Inca, es elegido por él mismo y en ocasiones podría tener su misma apariencia. 
(Garcilaso 2004 [1609]: 372). Como vemos en esta descripción de Garcilaso, es bien explícita la importancia del uso de dos vasos y de la mano derecha e izquierda en un ritual. En el mundo andino la dualidad tiene mucha importancia; todo tiene su contrario. Por ello, nos cuesta entender que en estas cinco tumbas aparezca el personaje principal con un solo vaso; ¿con qué objeto guardarían reciprocidad estos vasos? Sin duda es un tema que merece estudiarse con más detenimiento. Otra pregunta sería ¿por qué no se continuó en otros periodos con esta práctica de poner un vaso en una mano del difunto? Estamos seguros de que futuras excavaciones y estudios iconográficos, etnohistóricos e históricos nos ayudarán a comprender la importancia de la función de estos vasos, así como a entender quiénes son o qué significan los personajes representados en ellos, y si hacen referencia a la composición de la sociedad sicán, sus linajes, etnias o grupos de poder.

\section{Referencias bibliográficas}

Alonso Sagaseta de Ilurdoz, Alicia

1989 «Las momias de los Incas: su función y realidad social». Revista Española de Antropología Americana 19: 109-135.

1990a «Los Guauquis incaicos». Revista Española de Antropología Americana 20: 93-104.

1990 b «El kero: vaso ritual de los Incas». Espacio, Tiempo y Forma. Serie VII. Historia del Arte 3: 11-30.

Arriaga, Pablo José de

1999 La extirpación de la idolatría en el Perú [1621], estudio preliminar y notas de Henrique Urbano. Cuzco: Centro de Estudios Regionales Andinos «Bartolomé de Las Casas».

BerEnguer, José

2000 Tiwanaku: Señores del lago sagrado. Santiago de Chile: Museo Chileno de Arte Precolombino.

CARCEDo, Paloma

1989 «Anda ceremonial lambayecana: iconografía y simbología», en Lambayeque, José Antonio de Lavalle, ed., pp. 249-290. Lima: Banco de Crédito del Perú.

2012a «Los vasos en la orfebrería Sicán», en Cultura Sicán: Nuevas perspectivas, Izumi Shimada, ed. Lima: Editorial del Congreso. (En prensa).

2012b Personajes de élite en la orfebrería Sicán: deidades, linajes y ancestros Antonio Aimi, ed. Milán: Universidad de Milán. (En prensa).

CARcedo, Paloma e Izumi shimada

1985 «Behind the Golden Mask: Sican Gold Artifacts from Batan Grande, Peru», en Art of Pre-Columbian Gold: Jan Mitchell Collection, Julie Jones, ed., pp. 60-75. Londres: Weidenfel and Nicholson.

Cieza de León, Pedro de

1995 Crónica del Perú. Primera Parte [1553]. Lima: Pontificia Universidad Católica del Perú.

Cummins, Thomas B. F.

2004 Brindis con el Inca. La abstracción andina y las imágenes coloniales de los que- 
ros. Lima: Universidad Nacional Mayor de San Marcos - Embajada de los Estados Unidos de América - Universidad Mayor de San Andrés de La Paz.

Donnan, Christopher B.

1989 «En busca de Naylamp: Chotuna, Chornancap y el valle de Lambayeque», en Lambayeque, José Antonio de Lavalle, ed., pp.105-136. Lima: Banco de Crédito del Perú.

Flores, Jorge A., Elizabeth Kuon Arce y Roberto Samanez Argumedo

1998 Qeros: Arte inka en vasos ceremoniales. Lima: Banco de Crédito del Perú.

Garcilaso de la Vega, Inca

2004 Comentarios Reales de los Incas [1609], edición, índice analítico y glosario de Carlos Araníbar. México: Fondo de Cultura Económica.

Guamán Poma de Ayala, Felipe

1993 Nueva Crónica y Buen Gobierno [1615], edición y prólogo de Franklin Pease, vocabulario y traducciones de Jan Szeminski. México: Fondo de Cultura Económica.

Hernández Astete, Francisco

2012 Los incas y el poder de sus ancestros. Lima: Fondo Editorial, Pontificia Universidad Católica del Perú.

Kaulicke, Peter

2001 Memoria y muerte en el antiguo Perú. Lima: Fondo Editorial, Pontificia Universidad Católica del Perú.

Matsumoto, Go

2010 «Finding Ancestors in Archaeological Record: A Response to Whitley's 'Too Many Ancestors'». Ponencia presentada en la 38th Annual Midwest Conference on Andean and Amazonian Archaeology and Ethnohistory. Fort Wayn, 20-21 de febrero 2010. Manuscrito.

NARVÁEZ, Alfredo

1995 «El ave mítica lambayeque: Nuevas propuestas iconográficas (I)». Revista Utopía Norteña 1: 109-123.

SHIMADA, Izumi

1990 «Cultural Continuities and Discontinuities on the Northern North Coast of Peru, Middle-Late Horizons», en The Northern Dynasties: Kingship and Statecraft in Chimor, Michael E. Moseley y Alana Cordy-Collins, eds., pp. 297-392. Washington: Dumbarton Oaks.

1995 Cultura Sicán: Dios, riqueza y poder en la costa norte del Perú. Lima: EDUBANCO.

Shimada, Izumi, Jo Ann Griffin y Adon Gordus

2000 «The Technology, Iconography and Social Significance of Metals: A Multi-Dimensional Analysis of Middle Sican Objects», en Pre-Columbian Gold: Technology, Style and Iconography, Colin McEwan, ed., pp. 28-61. Londres: The Bristish Museum Press.

Shimada, Izumi, Ken-Ichi Shinoda, Julie Farnum, Robert Corruccini e Hirokatsu Watanabe 2004 «An Integrated Analysis of Pre-Hispanic Mortuary Practices: A Middle Sicán Case Study». Current Anthropology 45 (3): 369-402.

UCEDA, Santiago

2008 «Rituales funerarios de los reyes en una maqueta Chimú», en Señores de los Rei- 
nos de la Luna, Krzysztof Makowski, comp., pp. 314-317. Lima: Banco de Crédito del Perú.

VetTer, Luisa

2011 «Drink, Music, and Libation in Pre-Columbian Rituals: Drinking Vessels as Guiding Elements», en Inca: Gold Treasures in the Skeppsholmes Caverns, Kristian Göransson y Paloma Carcedo, eds., pp. 173-195. Estocolmo: Världskulturmuseerna.

Wester La Torre, Carlos

2010 Chotuna-Chornancap. «Templos, rituales y ancestros lambayeque». Lima: Proyecto Especial Naylamp, Unidad Ejecutora $n^{\circ} 111$ (Ministerio de Educación) Museo Arqueológico Nacional Bruning.

2012 La sacerdotisa lambayeque de Chornancap: Misterio e historia. Lima: Ministerio de Cultura. 